which culture sensitivity is substantially lower. Reassuringly we had no confirmed cases of ceftriaxone-resistant GC; yet it remains imperative to culture all patients prior to treatment to identify emerging resistant strains.

\section{P2.036 DETECTION OF HERPES SIMPLEX VIRUSES 1 AND 2 FROM CLINICAL SAMPLES WITH A FULLY-AUTOMATED PCR TEST ON THE COBAS ${ }^{\circledR} 4800$ SYSTEM}

doi:10.1136/sextrans-2013-051184.0301

K Ding, S Igdari, M Nagarajan, R Mababangloob, D Kosarikov, J Osiecki. Roche Molecular Systems, Pleasanton, CA, United States

Background Identification of genital herpes can have important implications for clinical management of HIV infected patients, immunosuppressed individuals, pregnant women, and individuals with HSV seronegative partners. This study was performed to establish preliminary performance characteristics for the newly developed cobas ${ }^{\circledR}$ HSV-1/2 Test by evaluating analytical sensitivity and specificity, specimen stability, and clinical performance compared with the BD ProbeTec ${ }^{\mathrm{TM}} \mathrm{HSV}-1 / 2$ Test.

Methods Analytical sensitivity was determined using viral culture spiked into a contrived background matrix at predetermined concentrations. Nine levels of viral target were evaluated using the prototype cobas ${ }^{\circledR}$ HSV-1/2 Test. These viral culture panels were also used to assess analytical sensitivity compared to the BD ProbeTec ${ }^{\text {тм }}$ HSV-1/2 Test. Preliminary exclusivity of the cobas ${ }^{\circledR}$ HSV-1/2 Test was evaluated with other herpes family viruses $(n=7)$ and a collection of microorganisms that might be found in lesion swab specimens $(\mathrm{n}=31)$. We also evaluated clinical lesion swab specimens (collected in UVT media for the BD Test and MSwab Media for the cobas $^{\circledR}$ Test). Transport and storage stability of anogenital lesion swab samples collected in MSwab media was assessed by testing specimens stored at RT, 2-8C and $-20 \mathrm{C}$.

Results The cobas ${ }^{\circledR}$ HSV-1/2 test displayed excellent analytical sensitivity of $150 \mathrm{vp} / \mathrm{mL}$ (HSV 1) and $100 \mathrm{vp} / \mathrm{mL}$ (HSV-2). When compared to the BD ProbeTec ${ }^{\mathrm{TM}}$ HSV-1/2 Test, superior sensitivity was observed for both HSV-1 and HSV-2 with the cobas ${ }^{\circledast} \mathrm{HSV}-1 / 2$ Test. Exclusivity studies showed no cross reactivity. The cobas ${ }^{\circledR}$ HSV-1/2 Test showed excellent performance with lesion swab specimens, observing a sensitivity and specificity of $100 \%$ and $100 \%$ for HSV-1 and $100 \%$ and $94 \%$ for HSV-2, respectively. Preliminary specimen stability studies for routine laboratory workflow indicate favourable performance.

Conclusion The cobas ${ }^{\circledR}$ HSV-1/2 test, run on the fully automated cobas $^{\circledast} 4800$ system, exhibited excellent preliminary performance characteristics, suitable for identifying low concentration HSV-1 and HSV-2 from anogenital lesions.

\section{P2.037 MULTICENTER EVALUATION OF THREE NOVEL $4^{\text {TH }}$ GENERATION HIV AG/AB COMBO ASSAYS: ABBOTT ARCHITECT, ROCHE HIV COMBI AND SIEMENS ADVIA CENTAUR}

doi:10.1136/sextrans-2013-051184.0302

'B Serhir, ${ }^{2} \mathrm{~J}$ Vincelette, ${ }^{3} \mathrm{E}$ Frost, ${ }^{4} \mathrm{M}$ Bergevin, ${ }^{5} \mathrm{C}$ Béliveau, ${ }^{6} \mathrm{D}$ Phaneuf, ${ }^{5} \mathrm{R}$ Sanfaçon, ${ }^{7} \mathrm{~A}$ Poirier, ' $\mathrm{F}$ Doualla-Bell, ' $\mathrm{C}$ Tremblay. 'Laboratoire de santé publique du Québec Institut national de santé publique du Québec, Ste-Anne-de-Bellevue, OC, Canada; ${ }^{2}$ CHUM - Hôpital St-Luc, Montréal, OC, Canada; ${ }^{3}$ CHUS - Hôpital Fleurimont, Sherbrooke, OC, Canada; ${ }^{4}$ Cité de la santé de Laval, Laval, OC, Canada; ${ }^{5}$ Hôpital Maisonneuve Rosemont, Montréal, OC, Canada; ${ }^{6}$ CHUM - Hôtel Dieu, Montréal, OC, Canada; 'Centre hospitalier affilié universitaire régional du CSSS de Trois-Rivières, Trois-Rivières, OC, Canada

Background Currently, 24 out of 39 laboratories in Quebec use the AxSYM HIV Ag/Ab Combo for HIV screening. This kit will be discontinued December 2013 and three novel $4^{\text {th }}$ generation screening
HIV assays (Architect, Roche Elecsys HIV Combi and ADVIA CENTAUR), approved by Health Canada, represent the alternative to AxSYM.

Objective and Methods: To investigate the performance of these 3 novel screening HIV Combo assays, in 6 clinical sites from Quebec. A total of 150 samples from patients with documented acute infection, a panel of 25 Seracare HIV-1 specimens, 3 quality control specimens (HIV-1.2 Ab POS, p24Ag POS, HIV-1.2 NEG), and 5577 sera from routine diagnostic patients were tested.

Results Sensitivity assessment- The 3 novel combos demonstrated comparable $100 \%$ sensitivity. Confirmed positive samples on the Architect and Roche Elecsys presented much greater S/CO values than AxSYM.

Specificity assessment- Each novel combo was compared separately to the AxSYM. Discordant results were confirmed using supplemental confirmatory assays.

The specificity of Architect was evaluated using 1099 specimens: 1095/1099 were non reactive, 3/1099 were reactive and 1/1099 was discordant. For Roche Combo, 3282 specimens were tested: $3222 / 3282$ were non reactive, 41/3282 were reactive, and 19/3282 were discordant. The Advia Centaur was evaluated using 1196 specimens, 1177/1196 were non reactive, 12/1196 were reactive and 7 were discordant.

Amongst the 66 specimens that were reactive with novel and AxSYM combos, 52 (79\%) were confirmed positive. All discordant results were confirmed negative. The 5494 specimens that were negative with both kits (novel and AxSYM) demonstrated lower S/ CO values on Architect and Roche than on AxSym.

\section{Abstract P2.037 Table 1}

\begin{tabular}{llll}
\hline & Architect & Roche & $\begin{array}{l}\text { Advia } \\
\text { Centaur }\end{array}$ \\
\hline Sensitivity (\%) & 100 & 100 & 100 \\
Specificity (\%) & 99.90 & 99.53 & 99.75 \\
Concordance with AxSYM (\%) & 99.90 & 99.42 & 99.41 \\
\hline
\end{tabular}

Conclusions The 3 novel HIV Ag/Ab Combo demonstrated good performance (sensitivity, specificity and concordance) with better segregation of positive and negative samples than AxSYM. All 3 kits represent a good alternative to the AxSYM.

\section{P2.038 HEPATITIS C VIRUS (HCV) ACUTE INFECTION IN HIV- INFECTED MSM DUE TO SEXUAL TRANSMISSION: DESCRIPTION OF SIX CASES}

doi:10.1136/sextrans-2013-051184.0303

J A Valencia, I de los Santos, J Sanz, C Sarria, A Salas. Hospital Universitario de la Princesa, Madrid, Spain

Background The transmission of HCV happens mostly across percutaneous exposure to blood. The role of the sexual transmission has not been well defined. In the last years HCV cases due to sexual transmission in HIV-infected MSM have been described. METHODS: Descriptive study of HIV-infected patients seen in our clinic, who showed HCV antibodies simultaneously with HCV-RNA-positive test and that previously had a negative test for antibody, without reporting injection drug use. Period of study: August 2011 to February 2013. RESULTS: We have diagnosed six cases. Age: $40.2 \pm$ 6.22 ; length of HIV infection: $9.83 \pm 6.17 \mathrm{yr}$. All the patients reported unsafe sex in the six previous months and all were on ART with HIV viral load $\leq 50$ copies/ml. HBV-coinfection:1/6 (16.6\%); Anti$\mathrm{HBs} \mathrm{Ab} \leq 10$ UI: $2 / 6$ (33.3\%). Previous sexual transmitted infections (STI): 5/6 (83.3\%). Baseline CD4 count: $686.2 \pm 198.3$ cells $/ \mu \mathrm{L}$. Median ASAT: $200.6 \pm 163$ IU/L; median ALAT: $491.8 \pm 334.4$ IU/1 Median HCV-RNA at presentation: $2.133 .293 \pm 1.703 .605 \mathrm{IU} / \mathrm{mL}$. 